\title{
Laparoscopic Liver Resection
}

\author{
Robert M. Cannon ${ }^{1}$ and Joseph F. Buell ${ }^{2}$ \\ ${ }^{1}$ University of Louisville Dept of Surgery, \\ ${ }^{2}$ Tulane University Dept of Surgery \\ United States of America
}

\section{Introduction}

Since the introduction of the laparoscopic cholecystectomy, there has been explosive growth in the field of minimally invasive surgery. Commonly accepted laparoscopic procedures have now come to include bariatric and anti reflux procedures, distal pancreatectomy, splenectomy, hernia repair, and colon resection. The adoption of laparoscopy to the field of liver surgery; however, has been slower to take off. Initial concerns included inadequate exposure and ability to attain hemostasis, fear of gas embolism, and doubts over the oncologic adequacy of the less invasive procedure. The earliest reports of laparoscopic liver surgery were limited to wedge resections for staging or isolated metastases(Lefor, AT \& Flowers, JL 1994). Laparoscopic liver resection finally started to gain serious widespread attention after publication of Cherqui's initial thirty patient experience(Cherqui, D et al 2000). Since that time, the field has seen explosive growth, with over 2,804 cases now described in the world literature(Nguyen, KT et al 2009). Despite its widespread acceptance, laparoscopic liver resection remains a daunting technical challenge suited to a relatively small number of centers that have taken the time and effort to develop concurrent expertise in both open hepatic surgery and laparoscopy. Once these hurdles are overcome; however, laparoscopic liver resection is a safe and highly effective procedure offering numerous patient benefits. In this chapter, we will describe the indications for laparoscopic liver resection, and outline the steps that should be taken by fledgling groups wishing to embark upon creating a laparoscopic liver resection program.

\section{Benign disease}

Benign liver tumors represent a diagnostic and therapeutic challenge. Traditionally, a highly conservative approach to benign hepatic tumors has been favored, owing to the historically high morbidity and mortality associated with open liver surgery. As operative and anesthetic techniques have improved, these hurdles have come down. Despite the increased safety of hepatic surgery, the indications for resection of benign hepatic tumors have changed little: symptomatic lesions, asymptomatic lesions at high risk of rupture or malignant degeneration, and inability to exclude malignancy nonoperatively. Because of concerns over oncologic adequacy, benign lesions represent the ideal starting point for a laparoscopic liver surgery program. Despite the attractiveness of minimally invasive surgery; however, surgeons should be cautioned that the ability to perform a laparoscopic resection should not change the indications for operation. 


\subsection{Hemangioma}

\subsubsection{Epidemiology and presentation}

Hemangioma represents the most common benign liver tumor, accounting for $5-20 \%$ of liver lesions(Buell, JF et al 2010). These tumors typically occur in females in the third through fifth decades. Symptoms typically do not occur until the tumors grow relatively large $(>5 \mathrm{~cm})$, and typically consist of abdominal pain resulting from stretching of Glisson's capsule. There have been reports of spontaneous, traumatic, or iatrogenic rupture. A rare consequence of hemangioma is a consumptive coagulopathy resulting from sequestration of platelets and clotting factors within the tumor vasculature known as the Kasabach-Merritt syndrome. There is no potential for malignant degeneration with hepatic hemangioma.

\subsubsection{Diagnostic evaluation}

Hemangiomas demonstrate a typical pattern of enhancement on triple phase contrast enhanced CT. The lesion appears as a well circumscribed hypodense mass with peripheral enhancement in the arterial phase that will progress toward the center of the lesion. This pattern is typically known as centripetal enhancement. Sensitivity of triple phase CT has been reported from $75-85 \%$ with specificity of 75-100\%(Trotter, JF \& Everson, GT 2001). Even better results have been reported with the use of magnetic resonance imaging, with reported sensitivity and specificity of up to $95 \%$ and $100 \%$, respectively (Semelka, RC et al 2001). Because of the highly vascular nature of these tumors, percutaneous biopsy of suspected hemangiomas is contraindicated.

\subsubsection{Indications for surgical resection}

As there is no malignant potential, symptomatic disease is the only generally accepted indication for surgical resection of hemangiomas. It should again be stressed that the availability of laparoscopy should not extend the indications for operation to asymptomatic patients. If pain is the indication for surgery, a thorough diagnostic workup is imperative to rule out other sources before attributing the symptoms to the hemangioma. The indication for surgery is more clear cut for large ruptured hemangioma, with patients often presenting in shock. Because of the dire consequences of rupture of large hemangioma, some surgeons would advocate the prophylactic resection of large lesions in patients with high risk occupations in areas remote from medical care. This opinion is controversial and should not be broadly applied.

\subsection{Focal nodular hyperplasia}

Focal nodular hyperplasia (FNH) is generally thought to arise as a hyperplastic proliferation of cells arising from an arterial malformation. This malformation may be congenital in nature such as telangiectasia or arteriovenous malformation, or may result from vascular injury (Paradis, V 2010; Wanless, IR et al 1985). Hyperplasia is thought to be a polyclonal process resulting from the hyperperfusion resulting from increased arterial flow (Gaffey, MJ et al 1996). The polyclonal nature of these lesions has significant impact on the radiographic evaluation of $\mathrm{FNH}$, as it is the only common benign lesion that appears hot on Technetium sulfur colloid scan. This is from increased uptake of tracer in Kuppfer cells present within the lesion. 


\subsubsection{Epidemiology, radiographic evaluation, and presentation}

$\mathrm{FNH}$ is typically an incidentally discovered lesion in women of late child bearing age, presenting most commonly from age 30 to 50. The female to male ratio has been reported at up to 8:1 (Mortele, KJ \& Ros, PR 2002). Unlike hepatocellular adenoma, FNH is not influenced by oral contraceptive use. The radiographic appearance of focal nodular hyperplasia is typically diagnostic. On triple phase computed tomography, FNH will show transient enhancement on arterial phase. On delayed imaging, the characteristic central scar then becomes hyperenhancing. This central scar represents the vascular pedicle of the lesion and is pathognomonic. The most common diagnostic difficulty is distinguishing FNH from adenoma, which may best be achieved by contrast enhanced MRI. In this setting, sensitivity and specificity can reach $97 \%$ and $100 \%$, respectively (Terkivatan, T et al 2006).

On histologic examination, FHN consists of benign hepatocytes arranged in a nodular pattern that are separated by fibrous septae originating in the central scar. Steatosis within the lesion may be evident (Paradis, V 2010). FNH is asymptomatic in upwards of $80 \%$ of cases (Buell, JF et al 2010). In very rare instances, these lesions may present with hemorrhage. There are no reported cases of malignant degeneration of FNH thus far. Because of this, there is no indication for resection of asymptomatic lesions, regardless of the size and number of lesions. Surgical resection is reserved for the rare cases in which the lesion is symptomatic or when the diagnosis is not secure.

\subsection{Hepatocellular adenoma}

Hepatic adenoma is a less common benign hepatic neoplasm, arising most commonly in women of child bearing age. There is a strong association between development of these lesions and oral contraceptive or androgenic steroid use. While the incidence is 0.1 per year per 100,000 patients who don't use oral contraceptives, there is a marked increase to up to 4 per 100,000 oral contraceptive users (Paradis, V 2010). The introduction of modern contraceptives with lower estrogen content has led to a decrease in incidence (Rooks, JB et al 1979). Less common risk factors for the development of hepatocellular adenoma include glycogen storage disease type I and type III (Micchelli, ST et al 2008)

\subsubsection{Radiographic features}

Though typically presenting as solitary lesions, adenoma may also be present as multiple lesions. Hepatic adenomas can grow quite large, with tumors of up to $30 \mathrm{~cm}$ reported in the literature. Ultrasonography typically lacks diagnostic utility for adenomas, which can range from hypo to hyper-echoic. Reported sensitivity of ultrasound is only around 30\%(Di, SM et al 1996). The CT appearance is that of a discrete, hypodense lesion showing enhancement on arterial phase followed by washout on later images. T1 weighted MRI will show a hypoto hyperintense lesion, while T2 images will show a lesion that is more isointense. Enhancement with gadolinium contrast is typically present on the arterial phase, with rapid washout in the venous phase. The fat content of these lesions creates a typical decrease in intensity on fat-suppressed MRI images (Motohara, T et al 2002).

\subsubsection{Clinical presentation}

Patients with hepatocellular adenoma are more likely to present with symptomatic disease than those with FNH. Epigastric or right upper quadrant pain is present in $25-50 \%$ of patients (Buell, JF et al 2010). Spontaneous hemorrhage is also relatively common with these 
lesions, occurring in over $20 \%$ of patients. These complications are more likely to occur in men and with lesions greater than $5 \mathrm{~cm}$ in diameter (Dokmak, $S$ et al 2009). Perhaps the most feared complication of hepatocellular adenoma is malignant degeneration. The risk has been reported in the range of 8-10\%(Dokmak, S et al 2009; Paradis, V 2010). Although $5 \mathrm{~cm}$ is the generally accepted size at which malignant degeneration becomes a concern, cases have been reported in lesions as small as $4 \mathrm{~cm}$ (Micchelli, ST et al 2008). There is also a greater risk of malignant degeneration in males and in patients with the metabolic syndrome. Malignancy within adenomas is typically discovered only after surgical resection.

\subsubsection{Management}

In the case of small adenomas in the setting of oral contraceptive use, a period of observation following the cessation of contraception is warranted. Surgical resection in this setting is then reserved for lesions which fail to regress or continue to grow after stopping the offending medication. As with other benign lesions, symptomatology that can clearly be attributed to the adenoma is also an indication for surgical resection. The presence of multiple adenomas, or adenomatosis, is an arbitrary distinction rather than a distinct pathologic subtype, thus indications for resection are the same as for solitary adenoma. Because of the well defined risk of malignant degeneration, there are also cases where resection of asymptomatic lesions is warranted. Generally accepted criteria include adenomas greater than $5 \mathrm{~cm}$ in size, or any adenoma in a male, regardless of size (Dokmak, $S$ et al 2009).

\subsection{Other benign lesions}

\subsubsection{Angiomyolipoma}

Angiomyolipoma is a rare benign tumor of mesenchymal origin. They most commonly occur in women and are discovered as incidental findings. Histologically, angiomyolipoma is composed of fat cells, blood vessels, and smooth muscle. CT imaging will show early enhancement that remains throughout the more delayed phases. Positive staining with HMB-45, with negative staining for cytokeratins 18 and 19, help to secure the diagnosis (Ding, GH et al 2011; Sturtz, CL \& Dabbs, DJ 1994). Malignant degeneration is very rare, as is rupture, with three cases reported in the world literature. Because of the rare nature of serious complications, an initially conservative management strategy of imaging follow up is recommended when the diagnosis is established. Recently proposed guidelines for surgical resection of angiomyolipoma are as follows: symptomatic disease, tumors greater than $6 \mathrm{~cm}$, tumors which grow on repeated imaging, tumors showing extrahepatic growth with risk of rupture, and inability to make a definitive diagnosis on imaging or biopsy (Ding, GH et al 2011).

\subsubsection{Nodular regenerative hyperplasia}

Nodular regenerative hyperplasia (NRH) is characterized by diffuse involvement of the liver by multiple regenerative nodules in the absence of significant fibrosis. The incidence of $\mathrm{NRH}$ in a large autopsy series has been reported at 2.6\% (Wanless, IR 1990). The disease typically manifests in the setting of systemic disorders such as Felty's syndrome or with the use of chemotherapeutic agents, of which azathioprine is the most common (Reshamwala, PA et al 2006). Complications are rare, as demonstrated by Wanless' series in which only 1 
of 64 patients suffered any form of complication from NRH. Specific treatment for NRH is not needed. Diagnosis is made on liver biopsy, with reticulin staining being particularly helpful in identifying the changes of hyperplasia. Therapy, instead, is directed at treating the underlying disorder or withdrawing the offending medication.

\subsubsection{Inflammatory pseudotumor}

Inflammatory pseudotumor of the liver is a benign reactive process, the pathogenesis of which is unclear. In the majority of cases in the literature, an infectious agent was found to be the causative agent. Symptoms, when present, are generally nonspecific including body pain, fever, weight loss, leukocytosis, and elevated transaminases. CT findings are generally not specific for the diagnosis, although spontaneous regression on followup imaging in 4-6 weeks is commonly reported to occur (Seki, S et al 2004). Histological features include replacement of liver parenchyma by densely hylanized collagenous tissue and chronic inflammatory infiltrates. These features are missed on FNA, making core needle biopsy critical for accurate diagnosis (Tsou, YK et al 2007). In a review of eight cases, Tsou et al have suggested that inflammatory pseudotumor may best be thought of as a variant of a healing liver abscess. Thus, treatment consists of antibiotic therapy and nonsteroidal antiinflammatory drugs. With appropriate therapy, the lesion can be expected to spontaneously regress. Surgical therapy is thus reserved for cases with severe symptoms or when malignancy is unable to be reliably excluded.

\subsection{Technical considerations for resection}

The majority of benign liver lesions are asymptomatic, leaving surgical resection as an appropriate therapy only in cases of symptomatic disease that is clearly attributable to the lesion, or when the diagnosis remains in doubt following appropriate workup. The exception is for hepatocellular adenoma, where the risk of malignant degeneration mandates resection for lesions larger than $5 \mathrm{~cm}$ or cases occurring in men.

\subsubsection{Patient positioning}

There are three commonly used patient positions employed in laparoscopic liver resection: supine, lateral decubitus, and the so-called French position in which the patient is supine with the legs in stirrups and the surgeon is positioned between the patient's legs. The appropriate position is determined based on the location of the tumor, and the surgical technique to be employed. The French position has the advantage of allowing the surgeon to operate with both hands while assistants can retract from either side of the table. The supine position is best employed when approaching lesions on the left lobe or right anterior sector of the liver. The lateral decubitus position places the patient recumbent on their left side at an angle of sixty degrees. This position allows access to the posterior segments of the right liver, as the left side down positioning prevents the liver from falling dependently into the operative field. When a hand port is to be employed, it is generally placed in the right upper quadrant as dictated by the position of the tumor being resected.

\subsubsection{Anesthesia and intraoperative care}

The use of low CVP anesthesia has been a critical factor in the improved safety of modern hepatic surgery. This technique mandates the use of central venous catheters and arterial lines for patient monitoring. During the parenchymal transection phase, central venous 
pressure is lowered to between 2 and $4 \mathrm{mmHg}$ with the use of nitrates, nitrous oxide, and dieresis. Combined with the tamponade effect of pneumoperitoneum, this technique minimizes blood loss from venous parenchymal bleeding (Tranchart, $\mathrm{H}$ et al 2010). Concern has been raised over the possibility of carbon dioxide embolism during laparoscopic liver surgery; however, extensive use of $\mathrm{CO} 2$ as an intravenous contrast agent in interventional radiology procedures shows that these fears are probably overstated (Hawkins, IF \& Caridi, JG 1998). Argon embolism, on the other hand, is a legitimate fear, and we advocate against the use of the argon beam coagulator on hepatic parenchymal veins. Furthermore, it is prudent to lower insufflations pressures during use of the argon beam.

Minimization of blood product usage is another key component of intraoperative care. The use of intraoperative thromboelastography (TEG) allows for near real time assessment of the coagulation cascade with replacement of coagulation factors as appropriate. The cell saver is well accepted as a means of minimizing blood transfusion requirements during operation for benign indications. Cell saver use in the setting of malignancy is more controversial; however, the employment of adjunctive measures such as leukocyte depletion filters may minimize the burden of tumor cells in salvaged blood (Liang, TB et al 2008).

\subsubsection{Parenchymal transection techniques}

A number of parenchymal transection techniques have been described in the literature, with none of them showing clear superiority over the others. Which technique is ultimately chosen thus becomes dependent upon the individual surgeon's comfort level with a given technique. Here we describe two of the more common strategies: electrosurgical dissection and stapler hepatectomy.

Electrosurgical transection techniques rely upon the surgeon's ability to operate two devices simultaneously. The surgeon should use a device such as the Harmonic Scalpel or Enseal (Ethicon Endosurgery, Cincinnatti, $\mathrm{OH}$ ) in the dominant hand. This device is used to incise Glisson's capsule and for the majority of parenchymal transection. The device should not be fully introduced into the parenchyma to prevent tearing of large vessels. When active bleeding is encountered, it is immediately controlled with bipolar cautery forceps which are held in the surgeon's other hand. Larger vessels require the use of laparoscopic clips. The simultaneous use both devices is facilitated by sitting on a tall stool, which allows the surgeon to operate the foot pedals independently.

Our group has favored the use of stapler hepatectomy. This technique provides the advantage of more rapid parenchymal transection, without the need for prior control of individual hepatic vessels. The first centimeter of parenchyma is relatively devoid of major vessels, and is incised with electrosurgical devices as described above. The dissection then proceeds using the thin blade of the stapler as a dissector. Care must be taken to avoid inadvertent manipulation of the stapler during firing, which can lead to tearing of major vessels and subsequent hemorrhage. The use of hand assistance is helpful in stabilizing the stapler to prevent such complications. We have preferred the use of a $25 \mathrm{~mm}$ vascular staple load for parenchymal transection.

When intraoperative hemorrhage is encountered, the presence of a hand in the abdomen is highly beneficial in allowing digital control of bleeding vessels prior to attaining definitive hemostasis. The "quick stitch" as described by Koffron has proven highly useful in laparoscopic control of bleeding vessels. The quick stitch is a precut $10 \mathrm{~cm}$ suture with two vascular clips placed on the tail of the suture. After the suture is placed and hemostasis is obtained, the closure is secured by additional clips place on the proximal end. Should 
conversion be necessary during a pure laparoscopic procedure, it should initially be to a hand assist method rather than to full laparotomy. In all cases, conversion should not be viewed as a failure or complication, but rather as a measure of prudent judgment (Buell, JF et al 2009a).

\section{Laparoscopic liver surgery for malignancy}

After becoming comfortable with resection of benign lesions, the logical progression in the development of a laparoscopic liver program is the resection of malignant lesions. These lesions require an increased degree of skill on the part of the surgeons in order to attain adequate margins and maintain oncologic adequacy. The presence of cirrhosis in the setting of HCC or steatohepatitis following neoadjuvant chemotherapy for colorectal metastasis make proper patient selection and timing of operation critical. The consideration of adjunctive techniques such as transarterial chemoemboliztion for preoperative downstaging also becomes important. Here, we will discuss laparoscopic management of the two most common malignant hepatic tumors: colorectal metastases and hepatocellular carcinoma.

\subsection{Colorectal metastases}

Colorectal metastases are the most common malignant hepatic tumor. Results following open resection of these lesions have been excellent, with 5 year survival rates exceeding $50 \%$ in many centers (House, MG et al 2010). Such outcomes have set a high standard by which laparoscopic resection must be measured. The adoption of laparoscopy to this field has been hindered by concerns of tumor seeding at port sates and the possibility of missing extrahepatic lesions by inadequate inspection of the peritoneal cavity(Hsu, TC 2008; Johnstone, PA et al 1996). These hurdles have slowly been brought down, and laparoscopic resection is now a standard part of the therapeutic arsenal for hepatic malignancy.

\subsubsection{Patient selection}

Patient selection criteria for laparoscopic resection of colorectal metastases are similar to those applied for open resection. Initial evaluation requires precise definition of tumor anatomy and exclusion of extrahepatic disease. We favor triple phase CT as the initial radiographic evaluation. When combined with digital arterial reconstruction, evaluation of aberrant vascular anatomy, which can be present in nearly half of all patients, is afforded. Evaluation of baseline liver function is performed with evaluation of bilirubin, INR, and albumin. A thorough history and physical exam is necessary to assess general fitness for major abdominal surgery. Tumor resectability is defined by the SSAT as an expected negative margin resection with preservation of at least 2 contiguous hepatic segments with adequate inflow, outflow, and biliary drainage and a future liver remnant of more than $20 \%$ for normal parenchyma(Charnsangavej, C et al 2006).

\subsubsection{Neoadjuvant therapy}

The use of chemotherapy and chemoradiation for metastatic colon and rectal cancer has become a mainstay of therapy. Modern chemotherapeutic regimens generally consist of 5fluorouracil combined with either oxaliplatin (FOLFOX) or irinotecan (FOLFIRI) have produced excellent response rates, and have been able to render $10-30 \%$ of previously unresectable disease amenable to surgical therapy. Agents such as cetuximab and bevacizumab have shown even better response rates. This efficacy is not without a price, 
however. Bevacizumab has a black box warning for spontaneous intestinal perforation. Traditional chemotherapeutic combinations are hepatotoxic, leading to the phenomenon of chemotherapy associated steatohepatitis (CASH). These considerations are important, as patients are often referred for hepatic surgery after neoadjuvant therapy has been initiated.

\subsubsection{Operative considerations and oncologic adequacy}

The most critical factor to producing positive outcomes is the attainment of negative operative margins (R0 resection). Facility with laparoscopic intraoperative ultrasound is a must for surgeons approaching malignant liver lesions, allowing for precise definition of tumor anatomy and planning of resection planes. As long as negative microscopic margins are obtained, there does not appear to be a minimum necessary margin width (Pawlik, TM et al 2005).

The approach to synchronous disease has received considerable attention, as it will be present in up to $25 \%$ of patients with colorectal liver metastases (Martin, RC et al 2009). There are three possible surgical strategies in this setting: the classic approach of colorectal resection followed by hepatectomy, a simultaneous resection of colorectal and hepatic disease, and a reverse strategy of metastasectomy followed by primary tumor resection. The drawback of the classic strategy is the delay in metastasectomy while patients receive adjuvant therapy. The combined strategy eliminates this delay, at the cost of greater surgical insult with possibly higher morbidity. The reverse strategy was described to eliminate the delay in metastasectomy while avoiding the surgical insult of the combined approach. With appropriate patient selection, groups from MD Anderson and the University of Louisville have demonstrated that the combined approach can be undertaken without increased morbidity and mortality. Brouquet's analysis of all three strategies found similar morbidity, mortality, and survival across groups, showing that no approach is clearly superior for all patients (Brouquet, A et al 2010).

With increasing worldwide experience of laparoscopic resection of colorectal metastases, the oncologic integrity of laparoscopy compared with open techniques has been shown to be comparable. Nguyen's review of the world literature found only one case of port site recurrence, which occurred in a case of metastatic renal cell carcinoma that ruptured prior to resection (Nguyen, KT et al 2009). Castaing's comparison of 60 patients undergoing laparoscopic resection and 60 patients undergoing open resection provided the first evidence of long term efficacy of laparoscopic resection for colorectal metastases. Five year survival in the laparoscopic group in this series was $62 \%$, which was comparable to the $56 \%$ five year survival in the open group. There was no difference in width of resection margins between groups, while the laparoscopic group included a greater percentage of patients undergoing combined hepatic and colorectal resection (Castaing, D et al 2009). Such results confirm that laparoscopic resection is a safe and effective alternative to open surgery for hepatic colorectal metastases.

\subsection{Hepatocellular carcinoma}

Hepatocellular carcinoma (HCC) is the sixth most common malignancy and the third most common cause of cancer death worldwide (Parkin, DM et al 2005). In the United States, where chronic hepatitis $\mathrm{C}$ infection is the main risk factor, there has been an increase in the incidence of HCC over the past several decades (El-Serag, HB \& Mason, AC 1999). Most patients present with relatively advanced disease, making curative treatment such as resection and liver transplantation applicable in only $30-40 \%$ of patients in Western centers 
(Bruix, J \& Llovet, JM 2002). One of the major limiting factors in preventing resectability is impaired hepatic function, with the vast majority of cases in Western patients developing in the background of cirrhosis. Thus, appropriate patient selection becomes paramount in achieving successful outcomes. Because of these limitations, the role of laparoscopic liver resection has remained more limited than for other disease states.

\subsubsection{Patient selection}

Much of the patient selection process for resection of HCC centers around assessment of the underlying liver parenchyma. The Child-Pugh classification system provides a rough framework from which to base the selection process. In generally, Child A patients are able to tolerate limited forms of resection, while Child B and C patients are typically referred for more palliative procedures such as systemic therapy or transarterial chemoembolization. In the West, assessment is directed at determining the presence of significant portal hypertension. Generally, patients with hepatic-venous pressure gradient of less than 10, esophageal varices of no greater than grade 1, and platelet counts of over 100,000 are considered acceptable risk. In addition, bilirubin levels must be normal.

A common technique in Eastern centers is the assessment of indocyanine green clearance rate (ICG). This technique involves the injection of an organic dye which is then measured in the peripheral blood after a 15 minute interval. Clearance of the dye is used as a surrogate for hepatic metabolic function. ICG retention of no more than $10-20 \%$ is considered to be acceptable. Using this technique in 1056 consecutive patients with normal bilirubin and no ascites, Imamura has been able to achieve hepatic resection with zero operative mortality (Imamura, $\mathrm{H}$ et al 2003).

Advances in imaging technology have lead to the increasing use of systemic liver volumetry as a preoperative risk assessment tool. A future liver remnant to standard liver volume ratio of greater than $20 \%$ is considered safe in patients with healthy liver parenchyma, while ratios of $30-40 \%$ are considered necessary for patients with compensated cirrhosis. An insufficient future liver remnant may be addressed with the use of adjunctive techniques such as portal vein embolization, which will be discussed in greater detail in the section on resection in cirrhotics.

Tumor related factors that preclude surgical resection include extrahepatic disease and invasion of the main portal vein, vena cava, and common hepatic artery. Multinodular disease that can't be resected with an adequate future liver remnant is also a relative contraindication to resection, although there is a role for resection of the dominant lesion with radiofrequency ablation of the remaining disease in highly selected cases. Although size alone is not a criteria for resectability, there is a practical limit to the size of lesion that can be safely approached laparoscopically. The recent international position statement for laparoscopic liver surgery recommends limitation of the laparoscopic approach to tumors $<5 \mathrm{~cm}$ in diameter for all but the most experienced of centers (Buell, JF et al 2009a).

\subsubsection{Technical considerations and oncologic adequacy}

Unlike the case of hepatic colorectal metastases, there does appear to be a benefit to wider surgical margins in patients with HCC. For patients with solitary HCC lacking vascular invasion, a margin of at least $2 \mathrm{~cm}$ has proven beneficial in a randomized controlled trial setting. Furthermore, the tendency of HCC to spread via the portal venous system favors the use of planned anatomic resection in patients with adequate hepatic reserve. The inability to perform anatomic resection should not be considered a contraindication, however, as more 
limited resection as been shown to be beneficial in the setting of cirrhosis (Rahbari, NN et al 2011).

Despite the limitations imposed by the greater difficulties in technical resection and patient selection, laparoscopic resection has proven to be a safe and effective alternative to open surgery in appropriately selected patients. Lai has demonstrated 5 year survival of $50 \%$, with disease free survival of $36 \%$, while Dagher has shown 5 year overall and disease free survival of $64.9 \%$ and 32.2\%, respectively (Dagher, I et al 2010; Lai, EC et al 2009). Others have shown laparoscopic resection to be associated with lower morbidity and postoperative ascites compared to open resection (Belli, G et al 2009b). Although hepatocellular carcinoma in the setting of cirrhosis represents the most difficult of diseases to approach via laparoscopy, these results show that the technique is safe and effective when performed in centers that have acquired the appropriate experience.

\section{Laparoscopic resection in cirrhotics}

As noted above, the cirrhotic patient represents a unique challenge to the laparoscopic liver surgeon. The possibility of postoperative liver failure resulting from inadequate remnant liver function is a dreaded complication to be avoided at all costs. One technique that can potentially prevent this problem is the use of preoperative portal vein embolization (PVE). The effectiveness of PVE is based on the remarkable regenerative capacity of the liver. The technique involves occlusion of the tumor bearing segments of the liver, which induces hypertrophy in the remaining hepatic segments. Generally, reimaging 6 weeks after PVE is performed to assess the adequacy of hypertrophy to provide an adequate future liver remnant. Failure to achieve adequate hypertrophy indicates a severely diseased liver that is not amenable to resection.

A meta-analysis of PVE has been found that the procedure is safe and able to induce adequate hypertrophy to reduce post resection liver failure in a considerable proportion of patients (Abulkhir, A et al 2008). Preoperative PVE is currently recommended in cirrhotic patients with predicted future liver remnant of less than $40 \%$. For centers using ICG retention, values of $10-19 \%$ with a FLR of $40-60 \%$ also represents an indication for portal vein embolization (Rahbari, NN et al 2011).

For cirrhotic patients able to undergo liver resection, laparoscopy provides a number of unique benefits. The smaller incisions cause less disruption of the abdominal wall collateral circulation. As complete evacuation of ascites is not necessary for a laparoscopic procedure, intraoperative fluid shifts are lessened. This contributes to the reduction in postoperative ascites seen with laparoscopy compared to open hepatectomy (Dagher, I et al 2009; Gigot, JF et al 2002). Another unique benefit is the reduced adhesion formation following laparoscopic surgery. For patients undergoing resection of HCC, salvage transplantation remains an important option for recurrences that are within the Milan criteria. Laurent found that liver transplants following laparoscopic compared to open resection were performed in less time, with less blood loss and transfusion requirement (Laurent, A et al 2009). Similarly, Belli has found repeat hepatectomy following initial laparoscopic resection to be faster and safer, with less blood loss and risk of visceral injury (Belli, G et al 2009a).

\section{Development of a laparoscopic liver resection program}

The recent international consensus conference on laparoscopic liver surgery has developed guidelines for the establishment and credentialing of a laparoscopic liver surgery program 
(Buell, JF et al 2009b). Prior to embarking upon beginning a program in laparoscopic liver surgery, it is necessary to acquire experience with both advanced laparoscopy and open hepatic surgery. These requirements have made the widespread adoption of laparoscopic liver surgery appropriately slow. As advanced laparoscopy becomes an increasingly important part of general surgery training programs, these prerequisites will become less of a hurdle, with the expected more rapid acceptance of laparoscopic liver surgery.

After establishing the necessary expertise in laparoscopy and open hepatic surgery, the ideal starting point is small, benign lesions in the periphery of the liver. Extensive use of hand assistance is also critical in reducing the learning curve. Koffron has described the hybrid technique, in which mobilization of the liver is performed laparoscopically, and parenchymal transection is then performed in an open fashion through the hand port incision (Koffron, AJ et al 2007). He has termed this approach "laparoscopic liver surgery for everyone," and we agree that this approach represents an ideal starting point for a laparoscopic liver program.

Once comfortable with performing more limited resections, the next step in development is the performance of major, anatomic resections. In this setting, the left lateral segmentectomy is the ideal starting point. Although much attention is given to the parenchymal transection phase, it should be noted that the greatest risk for vascular injury and subsequent conversion to an open procedure is actually during the mobilization phase. The most commonly injured vessel in this setting is the phrenic vein, which must be carefully identified and avoided. Conversion, as we have emphasized previously, should not be viewed as a failure or complication. Instead, the decision to convert to an open or hand assisted procedure rather than continue with a potentially unsafe situation laparoscopically is a mark of good surgical judgment.

Experience with resection of lesions located in the peripheral segments of the liver provides a foundation of skills, including mobilization, transection, hemostasis, and laparoscopic ultrasound. Once this fundamental skill set has been developed thoroughly, the surgeon is then able to proceed to more difficult lesions. At this point, malignant and/or large lesions located in the right and posterior segments of the liver can then be approached in the culmination of programmatic development. We have found that facility with minor resections can be achieved in 30 to 50 cases. More difficult resections such as formal lobectomy and right posterior resection require an additional 60 to 80 cases to master. Thus, the road to development of a laparoscopic liver resection program is long and often arduous, but is highly rewarding to both the surgeon and the patient when properly travelled.

\section{Conclusion}

Nearly 15 years after first being described, laparoscopic liver resection has been gradually gaining acceptance in a number of centers worldwide. As the necessary skills in advanced laparoscopy and hepatic surgery become more widespread, we anticipate that the further adoption of laparoscopic liver resection will increase more rapidly. The maturation of long term series have proven the oncologic adequacy of the laparoscopic approach in a variety of settings. With the development of a greater number of surgeons who are proficient in laparoscopic liver surgery, many more patients will benefit from decreased blood loss, less postoperative pain, and shorter lengths of stay. From being a novel procedure practiced in only a handful of centers worldwide, laparoscopic liver resection is now established as a 
safe and effective technique in the therapeutic decision tree for patients with surgical disease of the liver. We believe that this acceptance will continue to grow to the point that the laparoscopic approach will, as has been seen with colon resection, eventually be adopted as the standard of care in appropriately selected patients.

\section{References}

Abulkhir, A et al Preoperative portal vein embolization for major liver resection: a metaanalysis Ann.Surg.2008;247(1):49-57

Belli, G et al Laparoscopic redo surgery for recurrent hepatocellular carcinoma in cirrhotic patients: feasibility, safety, and results Surg.Endosc.2009a;23(8):1807-1811

Belli, G et al Laparoscopic and open treatment of hepatocellular carcinoma in patients with cirrhosis Br.J.Surg.2009b;96(9):1041-1048

Brouquet, A et al Surgical strategies for synchronous colorectal liver metastases in 156 consecutive patients: classic, combined or reverse strategy? J.Am.Coll.Surg.2010; 210(6):934-941

Bruix, J \& Llovet, JM Prognostic prediction and treatment strategy in hepatocellular carcinoma Hepatology2002;35(3):519-524

Buell, JF et al The international position on laparoscopic liver surgery: The Louisville Statement, 2008 Ann.Surg.2009a;250(5):825-830

Buell, JF et al The international position on laparoscopic liver surgery: The Louisville Statement, 2008 Ann.Surg.2009b;250(5):825-830

Buell, JF et al Management of benign hepatic tumors Surg.Clin.North Am.2010;90(4):719-735

Castaing, D et al Oncologic results of laparoscopic versus open hepatectomy for colorectal liver metastases in two specialized centers Ann.Surg.2009;250(5):849-855

Charnsangavej, $\mathrm{C}$ et al Selection of patients for resection of hepatic colorectal metastases: expert consensus statement Ann.Surg.Oncol.2006;13(10):1261-1268

Cherqui, D et al Laparoscopic liver resections: a feasibility study in 30 patients Ann.Surg.2000;232(6):753-762

Dagher, I et al Laparoscopic hepatectomy for hepatocellular carcinoma: a European experience J.Am.Coll.Surg.2010;211(1):16-23

Dagher, I et al Laparoscopic versus open right hepatectomy: a comparative study Am.J.Surg.2009;198(2):173-177

Di, SM et al Natural history of focal nodular hyperplasia of the liver: an ultrasound study J.Clin.Ultrasound1996;24(7):345-350

Ding, GH et al Diagnosis and treatment of hepatic angiomyolipoma J.Surg.Oncol.2011

Dokmak, $\mathrm{S}$ et al A single-center surgical experience of 122 patients with single and multiple hepatocellular adenomas Gastroenterology2009;137(5):1698-1705

El-Serag, HB \& Mason, AC Rising incidence of hepatocellular carcinoma in the United States N.Engl.J.Med.1999;340(10):745-750

Gaffey, MJ et al Clonal analysis of focal nodular hyperplasia of the liver Am.J.Pathol.1996;148(4):1089-1096

Gigot, JF et al Laparoscopic liver resection for malignant liver tumors: preliminary results of a multicenter European study Ann.Surg.2002;236(1):90-97

Hawkins, IF \& Caridi, JG Carbon dioxide (CO2) digital subtraction angiography: 26-year experience at the University of Florida Eur.Radiol.1998;8(3):391-402 
House, MG et al Survival after hepatic resection for metastatic colorectal cancer: trends in outcomes for 1,600 patients during two decades at a single institution J.Am.Coll.Surg.2010; 210(5):744-745

Hsu, TC Intra-abdominal lesions could be missed by inadequate laparoscopy Am.Surg.2008;74(9):824-826

Imamura, $\mathrm{H}$ et al One thousand fifty-six hepatectomies without mortality in 8 years Arch.Surg.2003;138(11):1198-1206

Johnstone, PA et al Port site recurrences after laparoscopic and thoracoscopic procedures in malignancy J.Clin.Oncol.1996;14(6):1950-1956

Koffron, AJ et al Laparoscopic liver surgery for everyone: the hybrid method Surgery2007; 142(4):463-468

Lai, EC et al Minimally invasive surgical treatment of hepatocellular carcinoma: long-term outcome World J.Surg.2009;33(10):2150-2154

Laurent, A et al Laparoscopic liver resection facilitates salvage liver transplantation for hepatocellular carcinoma J.Hepatobiliary.Pancreat.Surg.2009;16(3):310-314

Lefor, AT \& Flowers, JL Laparoscopic wedge biopsy of the liver J.Am.Coll.Surg.1994; 178(3):307-308

Liang, TB et al Intraoperative blood salvage during liver transplantation in patients with hepatocellular carcinoma: efficiency of leukocyte depletion filters in the removal of tumor cells Transplantation2008;85(6):863-869

Martin, RC et al Simultaneous versus staged resection for synchronous colorectal cancer liver metastases J.Am.Coll.Surg.2009;208(5):842-850

Micchelli, ST et al Malignant transformation of hepatic adenomas Mod.Pathol.2008; 21(4):491-497

Mortele, KJ \& Ros, PR Benign liver neoplasms Clin.Liver Dis.2002;6(1):119-145

Motohara, $\mathrm{T}$ et al MR imaging of benign hepatic tumors Magn Reson.Imaging Clin.N.Am.2002;10(1):1-14

Nguyen, KT et al World review of laparoscopic liver resection-2,804 patients Ann.Surg.2009; 250(5):831-841

Paradis, V Benign liver tumors: an update Clin.Liver Dis.2010;14(4):719-729

Parkin, DM et al Global cancer statistics, 2002 CA Cancer J.Clin.2005;55(2):74-108

Pawlik, TM et al Effect of surgical margin status on survival and site of recurrence after hepatic resection for colorectal metastases Ann.Surg.2005;241(5):715-22, discussion

Rahbari, NN et al Hepatocellular carcinoma: current management and perspectives for the future Ann.Surg.2011;253(3):453-469

Reshamwala, PA et al Nodular regenerative hyperplasia: not all nodules are created equal Hepatology2006;44(1):7-14

Rooks, JB et al Epidemiology of hepatocellular adenoma. The role of oral contraceptive use JAMA1979;242(7):644-648

Seki, S et al A clinicopathological study of inflammatory pseudotumors of the liver with special reference to vessels Hepatogastroenterology2004;51(58):1140-1143

Semelka, RC et al Focal liver lesions: comparison of dual-phase CT and multisequence multiplanar MR imaging including dynamic gadolinium enhancement J.Magn Reson.Imaging2001;13(3):397-401

Sturtz, CL \& Dabbs, DJ Angiomyolipomas: the nature and expression of the HMB45 antigen Mod.Pathol.1994;7(8):842-845 
Terkivatan, $\mathrm{T}$ et al Focal nodular hyperplasia: lesion characteristics on state-of-the-art MRI including dynamic gadolinium-enhanced and superparamagnetic iron-oxideuptake sequences in a prospective study J.Magn Reson.Imaging2006;24(4):864-872

Tranchart, $\mathrm{H}$ et al Laparoscopic resection for hepatocellular carcinoma: a matched-pair comparative study Surg.Endosc.2010;24(5):1170-1176

Trotter, JF \& Everson, GT Benign focal lesions of the liver Clin.Liver Dis.2001;5(1):17-42, v

Tsou, YK et al Inflammatory pseudotumor of the liver: report of eight cases, including three unusual cases, and a literature review J.Gastroenterol.Hepatol.2007; 22(12):21432147

Wanless, IR Micronodular transformation (nodular regenerative hyperplasia) of the liver: a report of 64 cases among 2,500 autopsies and a new classification of benign hepatocellular nodules Hepatology1990;11(5):787-797

Wanless, IR et al On the pathogenesis of focal nodular hyperplasia of the liver Hepatology1985; 5(6):1194-1200 


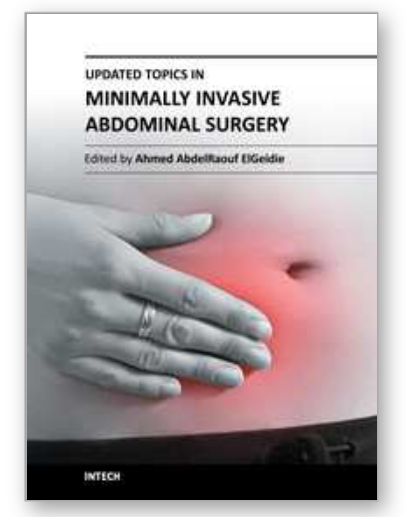

\author{
Updated Topics in Minimally Invasive Abdominal Surgery \\ Edited by Prof. Ahmed Elgeidie
}

ISBN 978-953-307-773-4

Hard cover, 246 pages

Publisher InTech

Published online 14, November, 2011

Published in print edition November, 2011

Updated topics in minimally invasive abdominal surgery provides surgeons interested in minimally invasive abdominal surgery with the most recent techniques and discussions in laparoscopic surgery. This book includes different topics covering a big variety of medical conditions with up-to-date information. It discusses many controversies in a clear and user-friendly manner. This book is made for young junior surgeons in training and also senior surgeons who need to know the most recent work in the field of laparoscopy. To make the material easily digestive, we provided the book with many figures and illustrations for different procedures and technical pearls.

\title{
How to reference
}

In order to correctly reference this scholarly work, feel free to copy and paste the following:

Robert M. Cannon and Joseph F. Buell (2011). Laparoscopic Liver Resection, Updated Topics in Minimally Invasive Abdominal Surgery, Prof. Ahmed Elgeidie (Ed.), ISBN: 978-953-307-773-4, InTech, Available from: http://www.intechopen.com/books/updated-topics-in-minimally-invasive-abdominal-surgery/laparoscopic-liverresection

\section{INTECH}

open science | open minds

\section{InTech Europe}

University Campus STeP Ri Slavka Krautzeka 83/A 51000 Rijeka, Croatia Phone: +385 (51) 770447

Fax: +385 (51) 686166 www.intechopen.com

\section{InTech China}

Unit 405, Office Block, Hotel Equatorial Shanghai No.65, Yan An Road (West), Shanghai, 200040, China 中国上海市延安西路65号上海国际贵都大饭店办公楼 405 单元 Phone: +86-21-62489820

Fax: $+86-21-62489821$ 
(C) 2011 The Author(s). Licensee IntechOpen. This is an open access article distributed under the terms of the Creative Commons Attribution 3.0 License, which permits unrestricted use, distribution, and reproduction in any medium, provided the original work is properly cited. 